\title{
Model for residential house element and material selection by neutrosophic MULTIMOORA method
}

\author{
Edmundas Kazimieras Zavadskas $^{\mathrm{a}, *}$, Romualdas Bausys ${ }^{\mathrm{b}}$, Birute Juodagalviene ${ }^{\mathrm{b}}$, \\ Inga Garnyte-Sapranaviciene ${ }^{\mathrm{c}}$ \\ a Department of Construction Technology and Management, Vilnius Gediminas Technical University Sauletekio Ave. 11, Vilnius LT-10223, Lithuania \\ b Department of Graphical Systems, Vilnius Gediminas Technical University Sauletekio Ave. 11, Vilnius LT-10223, Lithuania \\ c Department of Architectural Engineering, Vilnius Gediminas Technical University Sauletekio Ave. 11, Vilnius LT-10223, Lithuania
}

\section{A R T I C L E I N F O}

\section{Keywords:}

Residential house

Material selection

SWARA

MULTIMOORA

Neutrosophic sets

\begin{abstract}
A $\quad$ B $\quad S \quad T \quad R \quad A \quad C \quad T$
This article aims to create a theoretical evaluation model based on decision support methods for the residential house construction materials and elements selection. The research and analyses of most of the scientists are invoked on individual elements and materials of the building, which have an impact on different aspects of sustainability. Meanwhile, the integrated model covering all the key elements and materials of the single-family residential house has not been implemented. Thus, the problem of development of the general composite model of the element and material selection of single-family buildings is acute in many countries around the world.

Our study assessed the specific technical parameters related to building materials: cost, thermal bridging, and load-bearing capacity, the outer material selection according to localisation, environmental performance, durability, weight. SWARA (Step-wise Weight Assessment Ratio Analysis) approach is applied to decision making to calculate the relative importance of the criteria. A single-valued neutrosophic set governs the proposed new extension of MULTIMOORA (Multiobjective Optimisation by Ratio Analysis Plus Full Multiplicative Form) method and allows to deal explicitly with the indeterminacy of the initial information. Our proposed new theoretical composite model for selection of elements, materials and other aspects of sustainability can be practically applied in creating the decision support system for the selection of single-family house elements and materials.
\end{abstract}

(C) 2017 Elsevier Ltd. All rights reserved.

\section{Introduction}

The common tendency of the last decade is a growing proportion of society that can afford to build an individual space-a single family residential house. This trend can also be distinguished in EU countries (Eurostat, 2014). This direction is related to the changes in urban design tendencies and people's desire to have a closer relationship with the natural environment. A single family residential house building sector consumes more and more of the world's existing sources; it should become a pioneer in other building areas showing sustainability possibilities.

In today's extremely fast-changing world, sustainable development is becoming one of the most important factors in defining high-quality buildings, which create a healthy environment for humans and reduce the negative impact on the environment. As in other spheres of life, in the construction industry, the concept of sustainable development encompasses three main stages: economic (Lizana et al., 2016), social (Kamali and Hewage, 2017) and environmental (Holmstedt et al., 2017; Kosanovic and Fikfak, 2016).

Currently, buildings, building blocks and their impact on the environment can be measured using the building certification systems: BREEAM (Building Research Establishment Environmental Assessment Methodology), LEED (Leadership in Energy and Environmental Design), etc. Meanwhile, these particular methods are not widely used in the design of single-family residential houses. It results from the lack of models and sophisticated, complex assessment of most of the criteria of design.

The research mainly deals with the sustainability aspects of the buildings related to energy issues. Vucicevic et al. (2014) examined the sustainability of different types of housing, and proposed solutions

\footnotetext{
* Corresponding author. (I. Garnyte-Sapranaviciene).

E-mail addresses: edmundas.zavadskas@vgtu.lt (E.K. Zavadskas), romualdas.bausys@vgtu.lt (R. Bausys), birute.juodagalviene@vgtu.lt (B. Juodagalviene), inga.garnyte@vgtu.lt 
related to energy policy and the environment, Lizana et al. (2016) also suggested the practical solutions for energy modernisation in residential buildings. Dezhi et al. (2016) examined the entirety of ecological and social criteria for assessment of the sustainability of public rental housing and (Oree et al., 2017) considered the increasingly strict requirements of environmental sustainability. Kosanovic and Fikfak (2016) also studied the impact of the inefficient use of land on environmental sustainability. Some researchers considered optimisation aspects of these type problems: Holmstedt et al. (2017) proposed the optimal criteria of assessment of urban sustainability; the set of optimal evaluation factors for buildings is created by the Pareto method (Pombo et al., 2016).

Furthermore, the sustainability of single-family houses is assessed by additional criteria as well (Rid et al., 2017; Pombo et al., 2016): being the comfort of living, security, privacy and well-being. On the other hand, one-family residential houses (the subject of the article) differ in uniqueness, complexity, costs, and many other aspects that are dependent on the decision-making and collaboration between the client, architect, and designer. Due to stricter energy efficiency requirements, the currently designed single-family residential buildings have to meet new requirements: additional parameters are introduced, related to the application of sustainability principles. This trend makes the stakeholders of single-family houses (designers, contractors, customers) interested in the elements of the building and selection of structural materials. As well, this tendency actualises a sophisticated approach to the materials' formation, taking into account the energy efficiency, safety, and aspects of aesthetics of the buildings. On the other hand, the construction industry offers a broad range of suitable building materials. Therefore, during the design phase, in the case of a single-family residential house, one can formulate a variety of designs of the houses, which further complicates the final selection of elements and materials.

Therefore, the application of multi-criteria mathematical methods for choosing building elements and materials to be used in a singlefamily residential house is becoming one of the key aspects. Different MCDM (Multiple Criteria Decision Making) methods are applied to various problems: assessment of the environmental impact of single-family houses with different load-bearing structures (masonry, log and timber frame) (Motuziene et al., 2016), selection of wall insulation materials (Baglivo et al., 2014), impact of wooden structures on environmental sustainability (Cuadrado et al., 2015), the alternatives for foundations of single-family houses (Turskis et al., 2016), a comparative analysis of energy and environmental performance due to the roof typology (Gagliano et al., 2015). In fact, MCDM approaches are the one subclass of the broader field, named by Decision support system (DSS). Decision support systems involve different information processing methods, like distinct regression models, various classification approaches, artificial neutral networks and so on (Chau and Wu, 2010; Taormina and Chau, 2015; Wang et al., 2015; Wu et al., 2010; Zhang and Chau, 2009a, b).

Selection of building elements and materials usually is governed by the country's legal instruments, as well as impacted by choice of traditions and the ever-increasing requirements of energy efficiency, the importance of durability and environment worldwide (Hester et al., 2017; EUR-Lex, 2010). The choice of materials for the wall element material is necessary regarding sustainability and the ever-changing changing energy efficiency requirements. Gori et al. (2016) developed the competent insulation structures by optimisation of the number and sequence of layers of external walls. The methodology designed by Baglivo et al. (2014) is based on the use of "green" building materials and local materials by the principles of sustainability in the cold climate zones. In the warm climate zones, the materials are selected in such a way that less energy would be consumed for cooling of buildings. To that end, the tests are carried out with phase change materials (PCMS), integrated into the structure of the walls of the building (Kuznik et al., 2016).

There have been virtually no changes in the structure of the foundations along with the changing energy requirements, but the environmental impact assessment of the heat bridge has become particularly important (Ciancio et al., 2013; Sandanayake et al., 2016). The structure of the top part of the house (roof), as well as the structure of the wall structure, has been affected by many alterations: cross-section rafter elements (loft cases), construction composition and roofing parameters (Ferrari et al., 2014). The durability of the roof and good thermal performance depend not only on humidity and air flow along the roof structure but also on the choice of coating material, colour, and shape (Alchapar and Correa, 2016). Raina et al. (2015) and (Turskis and Juodagalviene, 2016) took into account the acoustics and ergonomic requirements considering the staircase structure.

The house orientation affects the environmental and economic aspects of sustainability. It becomes simply impossible to insulate parts of the building to the required level for the cases when the building is not properly oriented geographically (Hee et al., 2015), or too much (or too little) heat penetrates it through windows or showcases during the summer, or facades, roofs (Han et al., 2017) bays, terraces or other elements. Environmental impact reduction (Ramírez-Villegas et al., 2016) is directly related to the decrement of building's energy costs.

It is noteworthy that the research and analyses of most of the scientists are invoked on individual elements and materials of the building, which have an impact on different aspects of sustainability. Meanwhile, the integrated model covering all the key elements and materials of the single-family residential house has not been implemented. Thus, the problem of development of the general model of the criteria of singlefamily buildings is acute in many countries around the world.

Applying MCDM framework to solve the real life engineering problems, we need initially to assess the different criteria and to determine the corresponding weights. SWARA method originally proposed to select sound dispute resolution method (Kersuliene et al., 2010). Later, this method has been successfully implemented to assess the vulnerability of the office buildings to the blast (Nakhaei et al., 2016b). Another aspect of the application of the MCDM framework is the selection the appropriate method to rank the considered alternatives. We have implemented MULTIMOORA method, which originally was proposed for the project management problems (Brauers and Zavadskas, 2010). Although the initial formulation of this approach was dedicated to the crisp type of the information, the new extensions of MULTIMOORA method were rapidly developed the actual engineering problems: the application of the data fusion methods instead of the dominance theory are considered in Altuntas et al. (2015), the solution of the material selection problem in biomedical applications is performed in Hafezalkotob and Hafezalkotob (2015, 2017), failure mode and effects analysis is presented in Liu et al., (2014). Recently, a lot of the research is devoted to the consideration of the uncertainty or "fuzziness" of the initial information. Therefore, some fuzzy extensions of MULTIMOORA method are also developed (Zavadskas et al., 2015a).

To solve the complex real-life practical problems, decision makers usually have to face the problem of taking into account the vagueness of the initial information. Although the different types of the fuzzy sets have been introduced and applied to the solution of the MCDM problems (Mardani et al., 2015), they cannot consider all forms of uncertainties that arise in the solution of the real engineering problems. Recently, a theory of the neutrosophic sets originally proposed by Smarandache (1999) has allowed dealing with "knowledge of neural thought", and this "neutral" component allow to introduce additional functionality to model uncertain phenomena of information. The existing methods governed by fuzzy sets and their particular types are not convenient to solve decision-making problem with neutrosophic information. By the logic of the neutrosophic sets, each aspect of the problem is represented by the degree of the truth $(T)$, a degree of the indeterminacy $(I)$ and a degree of the falsity $(F)$. In contrast to intuitionistic fuzzy sets where the degree of the uncertainty depends on the degree of membership and the degree of non-membership, by neutrosophic logic the value of the indeterminacy degree is independent of truth and falsity degrees. The researchers proposed the new extensions that are dedicated to performing under neutrosophic set environment. The new application 
of the single-valued neutrosophic sets for WASPAS (Weight Aggregated Sum product Assessment) method was developed in Zavadskas et al. (2015b), for COPRAS (Method of Multiple Criteria Complex Proportional Assessment) method-in Bausys et al. (2015). This new approach WASPAS-SVNS (Weight Aggregated Sum product AssessmentSingle-Valued Neutrosophic Set) gives the opportunity to represent and model the indeterminacy of the initial information explicitly. The new extension of VIKOR (Visekriterijumska Optimizacija I Kompromisno Resenje) method for the solution of the multicriteria decision-making problems, namely VIKOR-IVNS, has been proposed by Bausys and Zavadskas (2015). This extension is developed under the environment of the interval-valued neutrosophic sets.

Section 2 of this article is concerned with the selection of building element and materials' for a single family residential house. Section 3 deals with the alternatives' selection in association with different customer needs. The case study is concentrated on Lithuania building sector, but it is easily adaptable to the other world countries. Experts' chosen the assessment criteria for single family house dominant materials were performed by the comparison by SWARA method. The essence of the proposed approach consists of the fusion of the operational functionality of single valued neutrosophic sets algebra, and the traditional crisp MULTIMOORA-SVNS (Multiobjective Optimisation by Ratio Analysis Plus Full Multiplicative Form-Single-Valued Neutrosophic Set) approach suggested in Section 4. In Section 5, "Calculation results" as the numerical example the assessment of the residential house projects is performed. The obtained neutrosophic aggregated decision matrix is presented. The last section deals with these investigation conclusions.

\section{Building elements and materials selection for single family residential building}

In this section, we propose a complete theoretical model of selection of constructions and material for a single-family residential house by applying the MCDM framework. We are not dealing with individual structural elements and materials (bearing and exterior decoration) compatible with the principles of sustainability of the building, but rather with their integrated choice. Based on these characteristics, we can design the project satisfying the sustainability of single-family houses.

It follows from the overview of the works that the assessment of single-family houses is given too little attention. They usually deal with the sustainability either of environmental aspects of all types of buildings, groups of buildings, cities, or of particular building materials and elements. Typically, they analyse the following factors that make the physical structure of a home are sustainable or not: type, size, shape, position, orientation and location, material, construction. In the case of choosing a single-family residential house, the following are selected: land plot, constructive solution, load-bearing structural system and many other parameters relating to the cost of materials, structural load-bearing capacity, thermal resistance, environmental performance, durability and aesthetics. As a person spends half of his time in a house, the house must be not only sustainable but also beautiful and comfortable to live in, compliant with the technical, regulatory requirements applicable in the country.

In developing our theoretical model of integrated selection of constructions and materials for a single-family residential house, we have discussed and analysed the criteria relevant to the assessment of the sustainability of all buildings and selected the ones who are most applicable to single-family houses. Typical stages of selection of constructions and materials for a single-family residential house are presented in Fig. 1.

The examination started with the consideration of virtually all the possible criteria of selection of elements and materials. During the deliberations, we have rejected the assessment of items such as floors, internal partitions and ceiling, because they do not have a significant impact on the design process (Baglivo and Congedo, 2016). The criteria selected by the experts affect all the key elements of the building (Table 1). Ten independent qualified experts related with house design: five architects, four engineers and one designer, classified these criteria in order of importance.

According to the experts, the most important criterion of assessment is the cost of primary structures (walls, foundations, roof, ceiling, windows and stairs) $\left(c_{1}, c_{2}, c_{3}, c_{7}, c_{8}, c_{17}\right)$. In the designing and construction of sustainable residential houses, the cost should not be given the highest priority, but the market trends show that the cost still holds that position (Mulliner et al., 2013). The cost of wall blocks, foundations and other structural elements was measured by the labour and materials costs.

The foundations of structures are primarily designed to withstanding the load exerted by the walls, foundations and roof. Typically, the selection of construction of the foundation of single-family houses $\left(c_{2}, c_{4}, c_{12}\right)$ is not difficult due to adequate soil bearing capacity parameters, assessed for a single-family house. But the selection of the type of foundation should not only be seen through cost. The energy efficiency of the building is achieved not only by insulating building material with a thicker insulation layer; this indicator is closely related to the constructive solution and installation of foundations. The environmental impact of laying the foundations is also an important factor (Ciancio et al., 2013), in this study, the researchers present the sustainability guidelines and selection criteria. We have assessed the range of design of the foundations by the following criteria: cost $\left(c_{2}\right)$ and the potential of elimination of a thermal bridge $\left(c_{4}\right)$ and the environmental potential $\left(c_{12}\right)$.

In most countries around the world, a pitched roof is selected for a single-family house $\left(c_{3}, c_{9}, c_{10}, c_{15}, c_{19}\right)$. In this case, the roof structure comprises of rafters, trusses or beams. There are two cases of utilisation of space under a pitched roof: a cold loft or a warm loft (attic). Installation of a cold loft has an adverse impact on the elimination of the thermal bridge at the eaves node $\left(c_{9}\right)$, and hence the sustainability of the entire house. Therefore, in the case study, several options of the attic and roof insulation were selected.

Contrary to the case of cold loft, bigger cross-section for roof bearing elements was selected not for bearing capacity but taking into account working installation of the residential premise. In attic case, the insulation layers are installed between the roof bearing structures or on the warm side. In the latter case, the total roof price $\left(c_{3}\right)$ increases but at the same time durability $\left(c_{15}\right)$ increases. Selection of roofing material depends not only on aesthetic factor $\left(c_{19}\right)$ but also on the localisation of the building $\left(c_{10}\right)$.

Stairs $\left(c_{17}, c_{18}\right)$ installation and maintenance cost are determined not only by selected construction but also the by their form, space, decoration, handrails and other parameters (Raina et al., 2015). Floor slab design selection according to the price, in turn, affects the time and quality of installation $\left(c_{7}\right)$. In criteria setup, we predicted floor slab weight $\left(c_{21}\right)$. It is clear that every kilogramme of the house weight is the load onto the soil, leading to the more complex construction of foundations. House floor slab is that element which can significantly reduce the weight of the building.

Selection of wooden or plastic windows affects their price not only during construction but also during operation. All windows and doors are cold bridges, without which the house will not exist, so they are not evaluated (only cold bridges in foundation and roof components were assessed).

The criteria are evaluated in the house walls bearing capacity $\left(c_{6}\right)$. Bearing capacity differences of porous concrete, expanded clay or brick walls influence shape, size and position of other structural elements. Eg., if the walls bearing capacity is insufficient, it can be difficult for the customer to change the indoor spatial zones.

The designed house can be built in different locations; therefore the localisation $\left(c_{5}, c_{10}\right)$ factor (Han et al., 2017) must be included in the set of criteria of the sustainable single family residential. Wall materials (Motuziene et al., 2016; Baglivo et al., 2014), roofing (Gagliano et al., 2015), window orientation and size (Hee et al., 2015) and even building 
Evaluation of single-family building complex material selection

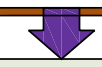

Determination of the most important evaluated parameters (materials and components)

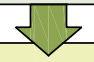

Determination of assessed alternative criteria' values (euro, scores, MPa, kg)

Indicators grouping by common peculiarities

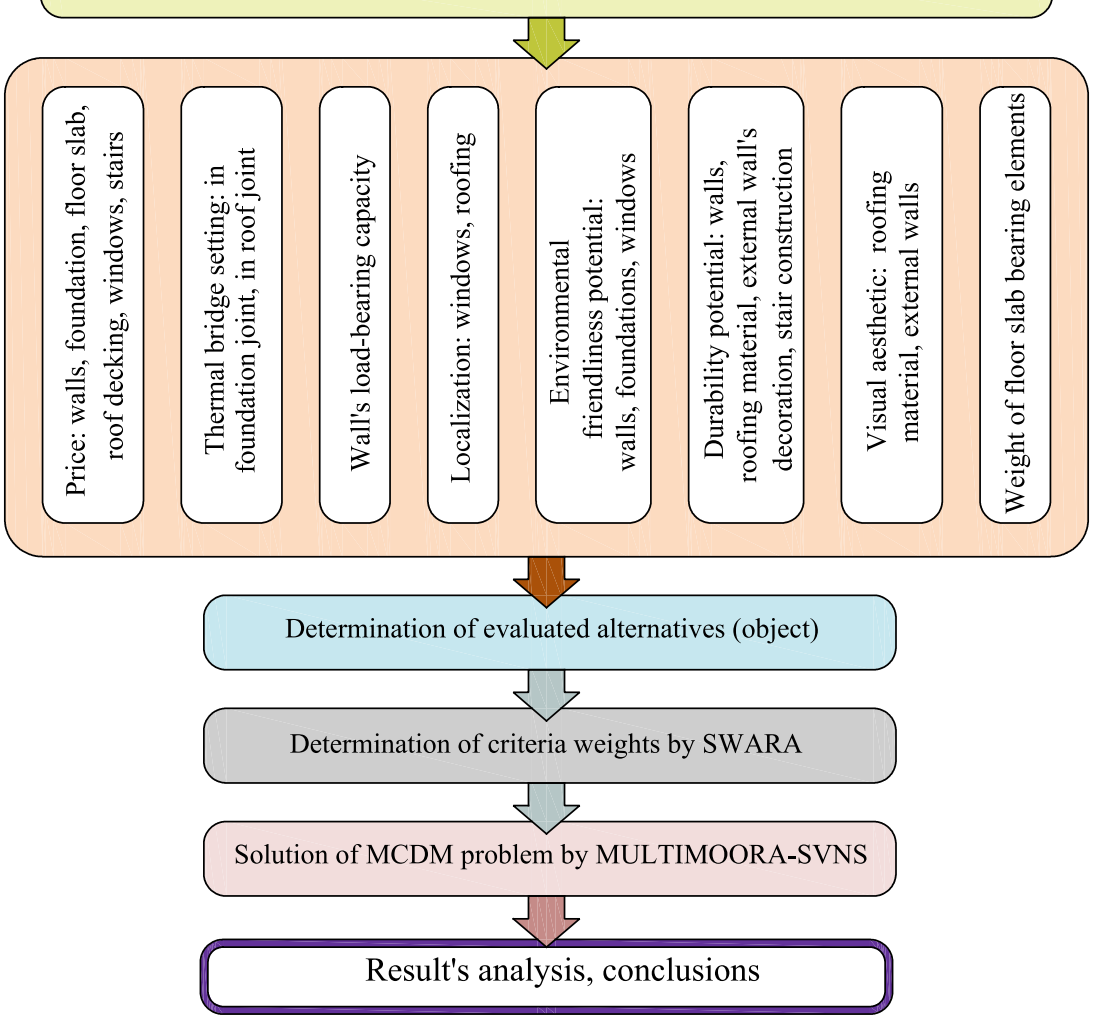

Fig. 1. Complex assessment model for single family house materials' and elements' selection.

Table 1

Criteria $\left(c_{1}-c_{21}\right)$ sorted by relevance.

\begin{tabular}{lll}
\hline$c_{1}-c_{21}$ & Min/max & Criteria titles \\
\hline$c_{1}$ & Min & Wall, $1 \mathrm{~m}^{2}$ price without decoration \\
$c_{2}$ & Min & Foundation corresponding to technical requirements, $1 \mathrm{~m}^{3}$ price \\
$c_{3}$ & Min & $\underline{\text { Roof-bearing elements, corresponding to the technical requirements, } 1 \mathrm{~m}^{2}}$ \\
$c_{4}$ & Min & The size of the thermal bridge in foundation, scores \\
$c_{5}$ & Max & Window target orientation (insolation), scores \\
$c_{6}$ & Max & Wall load-bearing capacity, MPa \\
$c_{7}$ & Min & $\underline{\text { Floor slabwithout floor covering, } 1 \mathrm{~m}^{2} \text { price }}$ \\
$c_{8}$ & Min & $\underline{\text { Window constructional solution, } 1 \mathrm{~m}^{2} \text { price }}$ \\
$c_{9}$ & Min & Rhe of the thermal bridge in roof, scores \\
$c_{10}$ & Max & Roofing materials' localisation factor, scores \\
$c_{11}$ & Max & Wall material environmental friendliness, scores \\
$c_{12}$ & Max & Influence of foundation installation environmental protection, scores \\
$c_{13}$ & Max & Windows' material environmental friendliness, scores \\
$c_{14}$ & Max & $\underline{\text { Wall material durability potential, scores }}$ \\
$c_{15}$ & Max & Roofing material durability potential, scores \\
$c_{16}$ & Max & $\underline{\text { External wall decoration durability potential, scores }}$ \\
$c_{17}$ & Min & $\underline{\text { Staircase constructional solution, price }}$ \\
$c_{18}$ & Max & $\underline{\text { Staircase' construction material durability potential, scores }}$ \\
$c_{19}$ & Max & Roofing aesthetic comprehension, scores \\
$c_{20}$ & Max & $\underline{\text { External wall decoration aesthetic comprehension, scores }}$ \\
$c_{21}$ & Min & $\underline{\text { Weight of floor slab bearing elements, weight }}$ \\
\hline & &
\end{tabular}


construction time depend on building location (residential area, farm fields, a house near the forest and others). Wall decorating materials are not included in the research criteria as for one-floor building with the attic they have no significant impact.

Environment $\left(c_{11}, c_{12}, c_{13}\right)$ is influenced not only by the used material or typologies of building elements, but also how they are produced, and their composition. During the erection, the construction of foundations does the greatest damage to the environment as it breaches of natural processes and vegetation. Plaster inside the building interacts with domestic encountered acids and steam, so this material must be resistant to the bacterial and fungal violation, and should not support combustion, should not produce smoke and toxins.

Each material or element has a particular function in the building and should meet specific requirements, including durability $\left(c_{14}, c_{15}, c_{16}, c_{18}\right)$. Nordic countries climate runs quite aggressively building constructions and materials; this affects their durability. The legislation regulates products' durability; there is provided that the masonry blocks used in the exterior walls should withstand the minimum of 25 cold and heat cycles during which the compressive strength should remain not diminished. Most of the blocks can withstand 50 cycles, but ceramic or porous concrete-only in 25-35 cycles. This parameter is of particular importance if a building under construction is not insulated in the same year, then one should choose materials, resistant to temperature change. The facade wall material and wall structure durability have the heavy reliance on the number of freeze-thaw cycles in a year (Toni et al., 2014). The roof durability and excellent thermal properties depend not only on the humidity and air movement in roof construction but also on the coating material, colour and shape (Alchapar and Correa, 2016).

Visual aesthetic $\left(c_{19}, c_{20}\right)$ criteria consist of only two components: roofing and exterior wall decoration. Selection of these materials and their mutual coherence has a significant impact not only on the house the urban context but also on customer's psychological comfort. In defining the roof and exterior wall, aesthetic appearance is also important to consider possible changes in material aesthetic (colour and texture) appearance in the long-term perspective.

\section{Alternatives of the single family residential house}

All alternatives for the material and element selection are constructed considering the single family residential house with the same architectural and the same geometrical parameters. The proposed strategy of the material and element selection for the house can be adapted to different cultures, climatically conditions and needs of the population.

\subsection{Peculiarities of alternatives}

A typical single-family residential house with five different material's alternatives was selected (Table 2). Options of building constructions and materials have been chosen considering to the original homeowners' given priorities and by designers' proposed products and materials. Building structures and materials selected as a separate case for the cold climate countries-Lithuania, according to the most approved option. The most appropriate solutions for the residential building were calculated and proposed by parameters identified by the expert assessments: the price, thermal bridges' elimination, and load-bearing capacity, external materials selection according to localisation, environmental friendliness, durability and weight.

Calculations (parameter selection) are carried under the same technical soil parameters was selected: soil-medium density gravel sand, soil density $-1.75 \mathrm{mg} / \mathrm{m}^{3}$, cohesive- $1 \mathrm{kPa}$, internal friction angle$36^{\circ}$, cone strength $-12 \mathrm{MPa}$, strain module-36 MPa. As well as for all alternatives the same architectural solution is considered without differences in the building area and height, the inclination of roof slope, it was assessed the localisation criterion (windows and roofing). The criteria also include the supporting structure of the building (cost, environmental friendliness and durability) and the external finishing of the building (walls and roof) (Table 3). Aspects related to the indoor home decor (internal partitions, floors, ceilings, other elements) are not taken into account as they are entirely individual and subjective factors (Baglivo and Congedo, 2016).

Building construction prices in this study are calculated by recommended prices for construction resources (March 2016). Market prices registered with the SPS Centre on behalf of the LR Minister of the Environment (SPCS, 2016). The price is considered as objective evaluation, and it is suitable to testing methodologies for future adaptability in single-family residential house construction practice. Material cost for square metres was selected instead of amounts needed for the entire object. Materials, their complete description and prices for square metres or metres, are of the utmost importance to the client in detailing constructional operations' quantities sheets and property cost estimates. Selection criteria are related to the coherence of fundamental aspects in building's architectural and constructional aspects.

Initially, ten independent experts selected 21 criteria $\left(c_{1}-c_{21}\right)$ and arranged them in order of importance, as some of the criteria have standard features, such as price, the environmental potential and others. In addition to the target of choice the excessive number of criteria should not dominate, it became apparent that most of the criteria could be combined $\left(x_{1}-x_{8}\right)$ according to their particular characteristics or assessments (Table 2). The following summarised weights combine both aspects: experts' opinions and data structure. As the problem has multiple criteria structure, it can be solved by MCDM method. The final decision-making matrix has form presented in Table 4.

\subsection{SWARA method}

The weighting evaluation is essential in solving many MCDM problems. Criteria weighting indicates how many times one indicator is more important than the other. The set task is solved by coherent and progressive pairwise comparison of criteria relative importance (SWARA) method (Kersuliene et al., 2010; Nakhaei et al., 2016a; Stanujkic et al., 2015). SWARA (Step-Wise Weights Assessment Ratio Analysis) the method is based (Nakhaei et al., 2016b) on an experts' assessment of the significance of the criteria in percentage.

The main steps of SWARA method for the criteria weights determination can be described as follows:

1. Constructing the total list of criteria;

2. Expert survey (experts arrange criteria according to rank, the most important index being listed as the first, etc.);

3. Calculation of the comparative importance of average value $s_{j}$;

4. Determination of characteristics of the comparative importance $k_{j}=s_{j}+1$

5. Determination of recalculated intermediate weight $w_{i}=\frac{w_{j-1}}{k_{j}}$;

6. Determination of the final weight (criterion importance) $q_{i}=$ $\frac{w_{j}}{\sum_{j=1}^{n} w_{j}}$, where $n$ is a number of criteria.

Experts arranged indicators in order of importance; therefore, it is considered that their views are consistent. Table 5 shows each participant of the expertise assessment comparing flanking criteria pairs.

Table 6 presents calculation results by SWARA method: the average values of indicators' relative comparative importance, coefficients of indicators' relative comparative importance, converted (intermediate) indicator weights and final indicators' weights.

\section{The neutrosophic MULTIMOORA method}

The essence of the proposed approach consists of the fusion of the operational functionality of single valued neutrosophic sets algebra and traditional crisp MULTIMOORA approach suggested by Brauers and 
Table 2

Parameters for single-family housing alternatives.

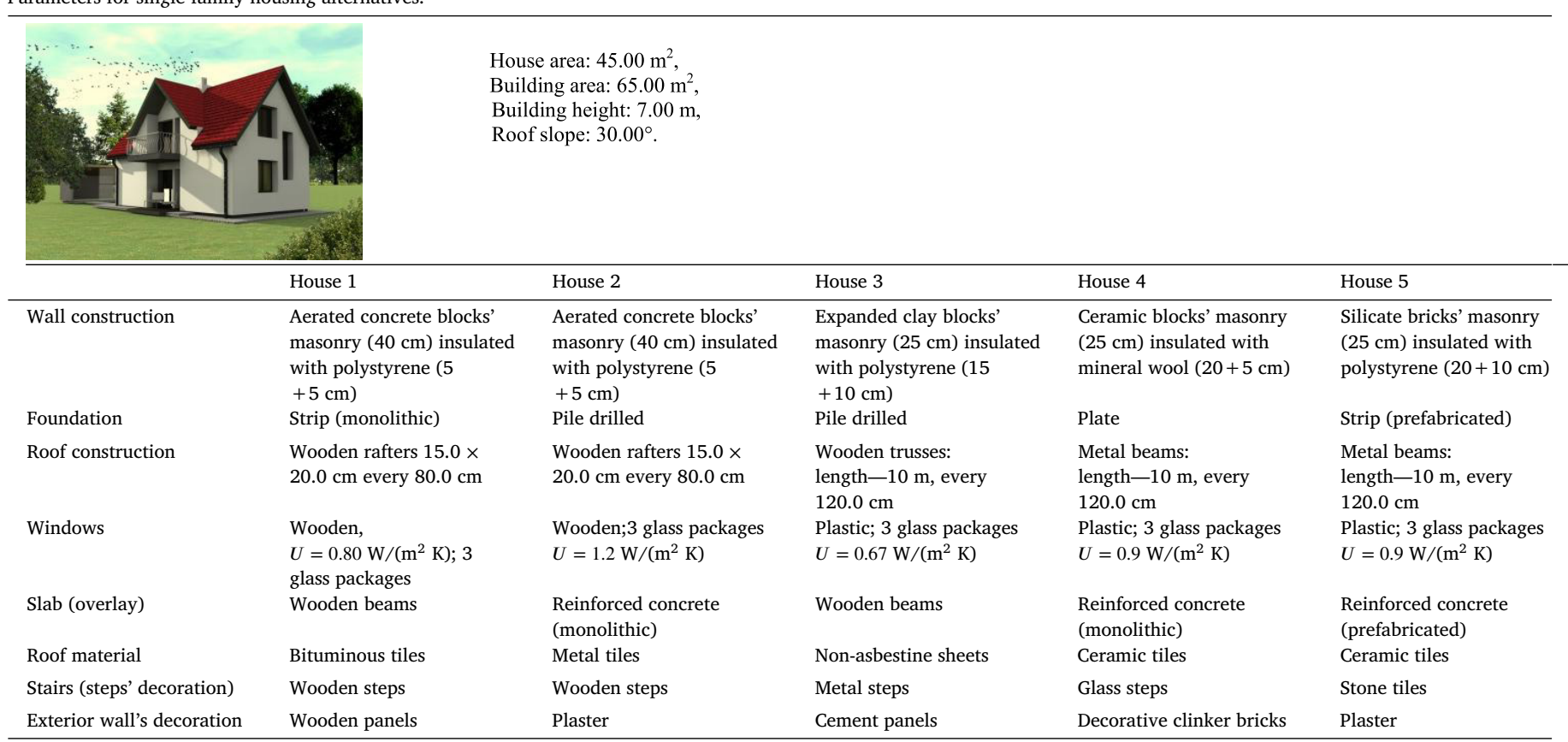

Table 3

Criteria significance by alternatives (separate criteria).

\begin{tabular}{|c|c|c|c|c|c|c|c|}
\hline Criteria & & & $\mathrm{A} 1$ & A2 & A3 & A4 & A5 \\
\hline Wall, $1 \mathrm{~m}^{2}$ price without decoration & $c_{1}$, & Euro & 52.31 & 52.31 & 51.73 & 76.32 & 61.84 \\
\hline Foundation corresponding to technical requirements, $1 \mathrm{~m}^{3}$ price & $c_{2}$ & Euro & 330 & 108 & 108 & 400 & 210 \\
\hline Roof-bearing elements, corresponding to the technical requirements, $1 \mathrm{~m}^{2}$ price & $c_{3}$ & Euro & 253 & 185 & 238 & 455 & 455 \\
\hline The size of the thermal bridge in foundation & $c_{4}$ & Scores & 4 & 3 & 3 & 0 & 7 \\
\hline Window target orientation (insolation) & $c_{5}$ & Scores & 7 & 2,5 & 8 & 5 & 5 \\
\hline Wall load-bearing capacity, MPa & $c_{6}$ & MPa & 5 & 5 & 5 & 15 & 15 \\
\hline 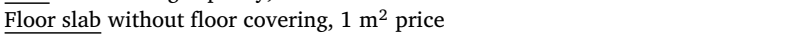 & $c_{7}$ & Euro & 98.3 & 52.1 & 98.3 & 52.1 & 323.8 \\
\hline Window constructional solution, $1 \mathrm{~m}^{2}$ price & $c_{8}$ & Euro & 235 & 235 & 190 & 150 & 150 \\
\hline$\overline{\text { The size of the thermal bridge in roof }}$ & $c_{9}$ & Scores & 1 & 1 & 2 & 8 & 8 \\
\hline Roofing materials' localisation factor & $c_{10}$, & Scores & 2 & 2 & 6 & 8 & 8 \\
\hline Wall material environmental friendliness & $c_{11}$, & Scores & 8 & 3.5 & 3.5 & 8 & 3.5 \\
\hline 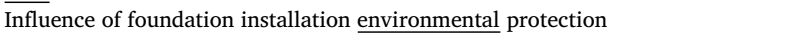 & $c_{12}$, & Scores & 3 & 8.5 & 8.5 & 10 & 4 \\
\hline Windows' material environmental friendliness & $c_{13}$, & Scores & 8 & 8 & 3 & 3 & 3 \\
\hline$\overline{\text { Wall material durability potential }}$ & $c_{14}$, & Scores & 3 & 3 & 6.5 & 8 & 10 \\
\hline$\overline{\text { Roofing material durability potential }}$ & $c_{15}$, & Scores & 1.5 & 6.5 & 4 & 8 & 8 \\
\hline$\overline{\text { External wall decoration durability potential }}$ & $c_{16}$, & Scores & 4 & 6 & 8 & 9 & 6 \\
\hline Staircase constructional solution & $c_{17}$, & Euro & 412 & 412 & 442 & 508 & 747 \\
\hline$\overline{\text { Staircase' }}$ construction material durability potential & $c_{18}$, & Scores & 5 & 5 & 7 & 5 & 8 \\
\hline Roofing aesthetic comprehension & $c_{19}$, & Scores & 2 & 6.5 & 4 & 8 & 8 \\
\hline External wall decoration aesthetic comprehension & $c_{20}$, & Scores & 7 & 5 & 10 & 8 & 5 \\
\hline$\overline{\text { Weight of floor slab bearing elements }}$ & $c_{21}$, & $\mathrm{kg}$ & 330 & 858 & 330 & 858 & 741 \\
\hline
\end{tabular}

Table 4

Criteria significance by alternatives (combined criteria).

\begin{tabular}{|c|c|c|c|c|c|c|c|}
\hline Criteria & & & A1 & A2 & A3 & A4 & A5 \\
\hline Price, $\min$ & $x_{1}$ & Euro & 1380.61 & 1044.41 & 1128.03 & 1641.42 & 1947.64 \\
\hline Thermal bridge parameter in constructional solution, min & $x_{2}$ & Scores & 2.5 & 2 & 2.5 & 4 & 7.5 \\
\hline Load-bearing capacity, max & $x_{3}$, & $\mathrm{MPa}$ & 5 & 5 & 5 & 15 & 15 \\
\hline Elements' selection according to localisation, max & $x_{4}$, & Scores & 4.5 & 2.3 & 7 & 6.5 & 6.5 \\
\hline Environmental friendliness potential, max & $x_{5}$ & Scores & 6.3 & 6.7 & 5 & 7 & 3.5 \\
\hline Durability potential, max & $x_{6}$, & Scores & 3.4 & 5.1 & 6.4 & 7.5 & 8 \\
\hline Visual aesthetic, max & $x_{7}$ & Scores & 4.5 & 5.8 & 7 & 8 & 6.5 \\
\hline Weight of floor slab bearing elements, min & $x_{8}$ & $\mathrm{~kg}$ & 330 & 858 & 330 & 858 & 741 \\
\hline
\end{tabular}

Zavadskas (2010). This new approach is named by MULTIMOORASVNS. As the most of the multicriteria decision-making techniques, the proposed method starts by the construction of the decision matrix $X$. The $x_{i j}$ elements of this matrix represent $i$ th criteria of $j$ th alternative send this matrix can be expressed by

$X=\left[\begin{array}{lll}x_{11} & \cdots & x_{1 m} \\ x_{n 1} & \cdots & x_{n m}\end{array}\right]$ 
Table 5

Relative importance assessment in indicators' pairs.

\begin{tabular}{clllllll}
\hline \multirow{2}{*}{ Expert } & \multicolumn{7}{l}{ Pairwise comparison of criteria relative importance } \\
\cline { 2 - 8 } & $x_{1 \leftrightarrow 2}$ & $x_{2 \leftrightarrow 3}$ & $x_{3 \leftrightarrow 4}$ & $x_{4 \leftrightarrow 5}$ & $x_{5 \leftrightarrow 6}$ & $x_{6 \leftrightarrow 7}$ & $x_{7 \leftrightarrow 8}$ \\
\hline 1 & 0.10 & 0.85 & 0.20 & 0.60 & 0.20 & 0.80 & 0.00 \\
2 & 0.05 & 0.70 & 0.10 & 0.80 & 0.05 & 0.70 & 0.20 \\
3 & 0.80 & 0.20 & 0.70 & 0.50 & 0.10 & 0.70 & 0.00 \\
4 & 0.60 & 0.05 & 0.80 & 0.30 & 0.05 & 0.00 & 0.10 \\
5 & 0.50 & 0.40 & 0.60 & 0.70 & 0.30 & 0.65 & 0.10 \\
6 & 0.10 & 0.20 & 0.00 & 0.00 & 0.80 & 0.00 & 0.85 \\
7 & 0.70 & 0.30 & 0.60 & 0.40 & 0.00 & 0.50 & 0.10 \\
8 & 0.00 & 0.50 & 0.10 & 0.20 & 0.70 & 0.00 & 0.75 \\
9 & 0.70 & 0.10 & 0.05 & 0.05 & 0.80 & 0.00 & 0.00 \\
10 & 0.00 & 0.60 & 0.10 & 0.30 & 0.50 & 0.20 & 0.80 \\
\hline
\end{tabular}

The first objective of the neutrosophic MULTIMOORA method is the ratio system. For the determination of this aim, the normalisation of the decision matrix initially is performed by vector normalisation approach.

$X^{*}=\frac{x_{i j}}{\sqrt{\sum_{i=1}^{m} x_{i j}^{2}}}$.

After normalisation, the neutrosophication step for the elements of the decision matrix is performed. The crisp values are transformed into single-valued neutrosophic members according to conversion rules that are presented in Table 7.

After this step, the neutrosophic decision matrix is constructed. The first objective of neutrosophic MULTIMOORA approach is calculated as follows

$Q_{j}=\sum_{i=1}^{g} w_{i}\left(x_{n}^{*}\right)_{i j}+\left(\sum_{i=g+1}^{n} w_{i}\left(x_{n}^{*}\right)_{i j}\right)^{c}$,

where $g$ elements correspond to members of the criteria to be maximised, $n-g$ correspond members of criteria to be minimised. Here single-valued neutrosophic members have the same form as in Peng et al. (2014)

$\left(x_{n}^{*}\right)_{1}=\left(t_{n 1}, i_{n 1}, f_{n 1}\right)$.

The multiplication of the neutrosophic number by scalar can be calculated as follows

$\lambda\left(x_{n}^{*}\right)_{1}=\left(1-\left(1-t_{n 1}\right)^{\lambda},\left(i_{n 1}\right)^{\lambda},\left(f_{n 1}\right)^{\lambda}\right)$.

The summation of the single-valued neutrosophic member in Eq. (3) is performed applying the following expression

$\left(x_{n}^{*}\right)_{1} \oplus\left(x_{n}^{*}\right)_{2}=\left(t_{n 1}+t_{n 2}-t_{n 1} \cdot t_{n 2}, i_{n 1} \cdot i_{n 2}, f_{n 1} \cdot f_{n 2}\right)$.

The second term in Eq. (3) corresponds to the complementary component of the single valued neutrosophic member and is determined as follows

$\left(x_{n 1}^{*}\right)^{c}=\left(f_{n 1}, 1-i_{n 1}, t_{n 1}\right)$.

The second objective of proposed neutrosophic MULTIMOORA method is calculated considering deviation is from the reference point
Table 7

Ruler of the transformation of the crisp number to the single-valued neutrosophic numbers.

\begin{tabular}{ll}
\hline Crisp terms (normalised) & SVNNs \\
\hline Extremely good $(\mathrm{EG}) / 1.0$ & $(1.00,0.00,0.00)$ \\
Very very good $(\mathrm{VVG}) / 0.9$ & $(0.90,0.10,0.10)$ \\
Very good $(\mathrm{VG}) / 0.8$ & $(0.80,0.15,0.20)$ \\
Good $(\mathrm{G}) / 0.7$ & $(0.70,0.25,0.30)$ \\
Medium good $(\mathrm{MG}) / 0.6$ & $(0.60,0.35,0.40)$ \\
Medium $(\mathrm{M}) / 0.5$ & $(0.50,0.50,0.50)$ \\
Medium bad $(\mathrm{MB}) / 0.4$ & $(0.40,0.65,0.60)$ \\
Bad $(\mathrm{B}) / 0.3$ & $(0.30,0.75,0.70)$ \\
Very bad $(\mathrm{VB}) / 0.2$ & $(0.20,0.85,0.80)$ \\
Very very bad $(\mathrm{VVB}) / 0.1$ & $(0.10,0.90,0.90)$ \\
Extremely bad $(\mathrm{EB}) / 0.0$ & $(0.00,1.00,1.00)$ \\
\hline
\end{tabular}

and the Min-Max Matrix of Tchebycheff norm

$\min _{j}\left(\max _{i}\left|D\left(r_{i}-w_{i}\left(x_{n}^{*}\right)_{i j}\right)\right|\right)$.

The reference point is determined as follows

$r_{i}=\max _{j}\left(w_{i}\left(x_{n}^{*}\right)_{i j}\right)$,

for the case of the criteria to by maximised and in the case of the criteria minimisation

$r_{i}=\min _{j}\left(w_{i}\left(x_{n}^{*}\right)_{i j}\right)$.

The comparison of the neutrosophic members is performed applying the score function

$S\left(\left(x_{n}^{*}\right)_{1}\right)=\frac{3+t_{n 1}-2 i_{n 1}-f_{n 1}}{4}$.

Therefore, in case of

$S\left(\left(x_{n}^{*}\right)_{1}\right)<S\left(\left(x_{n}^{*}\right)_{2}\right)$,

$\left(x_{n}^{*}\right)_{1}$ is smaller than $\left(x_{n}^{*}\right)_{2}$ and

$\left(x_{n}^{*}\right)_{1}<\left(x_{n}^{*}\right)_{2}$.

The distance measure between two single-valued neutrosophic sets is introduced as follows

$$
\begin{aligned}
D & \left(\left(x_{n}^{*}\right)_{1},\left(x_{n}^{*}\right)_{2}\right) \\
& =\sqrt{\frac{1}{3}\left(\left(t_{n 1}-t_{n 2}\right)^{2}+\left(i_{n 1}-i_{n 2}\right)^{2}+\left(f_{n 1}-f_{n 2}\right)^{2}\right)} .
\end{aligned}
$$

The third objective of the proposed neutrosophic MULTIMOORA method concerns with Full Multiplicities form, which embodies maximisation of the criteria as well as minimisation of the purely multiplicative utility function. Therefore, for each considered alternative can be constructed the overall utility, which can be determined or follows

$U_{j}=\frac{S\left(A_{j}\right)}{S\left(B_{j}\right)}$.

Table 6

\begin{tabular}{|c|c|c|c|c|}
\hline Indicator & $\begin{array}{l}\text { Average values of comparative } \\
\text { importance indicators, } s_{j \leftrightarrow j+1}\end{array}$ & $\begin{array}{l}\text { Coefficients of comparative } \\
\text { importance indicators, } k_{j}\end{array}$ & $\begin{array}{l}\text { Recalculated (intermediate) } \\
\text { indicators weights, } w_{j}\end{array}$ & $\begin{array}{l}\text { Final indicators } \\
\text { weights, } q_{j}\end{array}$ \\
\hline$x_{1}$ & - & 1.000 & 1.000 & 0.2895 \\
\hline$x_{2}$ & 0.355 & 1.355 & 0.738 & 0.2137 \\
\hline$x_{3}$ & 0.390 & 1.390 & 0.531 & 0.1537 \\
\hline$x_{4}$ & 0.325 & 1.325 & 0.401 & 0.1160 \\
\hline$x_{5}$ & 0.385 & 1.385 & 0.289 & 0.0838 \\
\hline$x_{6}$ & 0.350 & 1.350 & 0.214 & 0.0620 \\
\hline$x_{7}$ & 0.355 & 1.355 & 0.158 & 0.0458 \\
\hline \multirow[t]{2}{*}{$x_{8}$} & 0.290 & 1.290 & 0.123 & 0.0355 \\
\hline & & & 3.4540 & \\
\hline
\end{tabular}

Criteria weighting by SWARA method. 
Table 8

The decision matrix after neutrosophication step.

\begin{tabular}{|c|c|c|c|c|c|}
\hline Criteria & $\mathrm{A} 1$ & A2 & A3 & A4 & A5 \\
\hline$x_{1}(\min )$ & $(0.4209 ; 0.6186 ; 0.5791)$ & $(0.3184 ; 0.7316 ; 0.6816)$ & $(0.3439 ; 0.7061 ; 0.6561)$ & $(0.5005 ; 0.4993 ; 0.4995)$ & $(0.5938 ; 0.3592 ; 0.4062)$ \\
\hline$x_{2}(\min )$ & $(0.2654 ; 0.7846 ; 0.7346)$ & $(0.2123 ; 0.8377 ; 0.7877)$ & $(0.2654 ; 0.7846 ; 0.7346)$ & $(0.4246 ; 0.6131 ; 0.5754)$ & $(0.7961 ; 0.1539 ; 0.2039)$ \\
\hline$x_{3}(\max )$ & $(0.2182 ; 0.8318 ; 0.7818)$ & $(0.2182 ; 0.8318 ; 0.7818)$ & $(0.2182 ; 0.8318 ; 0.7818)$ & $(0.6547 ; 0.2953 ; 0.3453)$ & $(0.6547 ; 0.2953 ; 0.3453)$ \\
\hline$x_{4}(\max )$ & $(0.3568 ; 0.6932 ; 0.6432)$ & $(0.1824 ; 0.8588 ; 0.8176)$ & $(0.5551 ; 0.4174 ; 0.4449)$ & $(0.5154 ; 0.4769 ; 0.4846)$ & $(0.5154 ; 0.4769 ; 0.4846)$ \\
\hline$x_{5}(\max )$ & $(0.4820 ; 0.5270 ; 0.5180)$ & $(0.5126 ; 0.4811 ; 0.4874)$ & $(0.3825 ; 0.6675 ; 0.6175)$ & $(0.5356 ; 0.4466 ; 0.4644)$ & $(0.2678 ; 0.7822 ; 0.7322)$ \\
\hline$x_{6}(\max )$ & $(0.2412 ; 0.8088 ; 0.7588)$ & $(0.3617 ; 0.6883 ; 0.6383)$ & $(0.4539 ; 0.5691 ; 0.5461)$ & $(0.5320 ; 0.4521 ; 0.4680)$ & $(0.5674 ; 0.3989 ; 0.4326)$ \\
\hline$x_{7}(\max )$ & $(0.3112 ; 0.7388 ; 0.6888)$ & $(0.4011 ; 0.6484 ; 0.5989)$ & $(0.4840 ; 0.5239 ; 0.5160)$ & $(0.5532 ; 0.4202 ; 0.4468)$ & $(0.4495 ; 0.5758 ; 0.5505)$ \\
\hline$x_{8}(\min )$ & $(0.2205 ; 0.8295 ; 0.7795)$ & $(0.5734 ; 0.3899 ; 0.4266)$ & $(0.2205 ; 0.8295 ; 0.7795)$ & $(0.5734 ; 0.3899 ; 0.4266)$ & $(0.4952 ; 0.5072 ; 0.5048)$ \\
\hline
\end{tabular}

Table 9

The neutrosophic ratio system objective for the alternatives.

\begin{tabular}{llll}
\hline & $Q_{i}$ & $S\left(Q_{i}\right)$ & Rank \\
\hline A1 & $(0.7685 ; 0.2388 ; 0.2704)$ & 0.7551 & 4 \\
A2 & $(0.8214 ; 0.1865 ; 0.2188)$ & 0.8074 & 2 \\
A3 & $(0.8253 ; 0.1772 ; 0.2112)$ & 0.8149 & 1 \\
A4 & $(0.7625 ; 0.2251 ; 0.2283)$ & 0.7710 & 3 \\
A5 & $(0.6191 ; 0.3632 ; 0.3344)$ & 0.6395 & 5 \\
\hline
\end{tabular}

Here $A_{j}$ and $B_{j}$ components are calculated as

$A_{j}=\prod_{i=1}^{g} w_{i}\left(x_{n}^{*}\right)_{i j}, \quad B_{j}=\prod_{j=g+1}^{n} w_{i}\left(x_{n}^{*}\right)_{i j}$.

The first component $A_{j}$ represents the product of criteria of $j$ th alternative to be maximised and the second component $B_{j}$ corresponds to product of criteria of $j$ th alternative to be minimised. The multiplication of the separate single valued neutrosophic members is performed as follows.

$$
\left(x_{n}^{*}\right)_{1} \otimes\left(x_{n}^{*}\right)_{2}=\left(t_{n 1} \cdot t_{n 2}, i_{n 1}+i_{n 2}-i_{n 1} \cdot i_{n 2}, f_{n 1}+f_{n 2}-f_{n 1} \cdot f_{n 2}\right) .
$$

The final summarisation of all three objectives of the neutrosophic MULTIMOORA method is performed applying the dominance theory (Brauers and Zavadskas, 2011).

\section{Calculation results}

As the numerical example, the assessment of the residential house projects is performed. The obtained neutrosophic decision matrix is presented in Table 8.

The ratio system objective of neutrosophic MULTIMOORA approach for the alternatives is shown in Table 9.

The results of the neutrosophic reference point objective for the considered alternatives are presented in Table 10.

The results of the neutrosophic full multiplicative form objective for the considered alternatives are presented in Table 11.

The summarisation of all objectives obtained by neutrosophic MULTIMOORA approach is performed applying the dominance theory, and results are presented in Table 12.

According to the performed multi-criteria decision making it was received the best choice of materials for a single residential house; it is the alternative A-4 (House 4). Despite the fact that the major elements price for one sq. $\mathrm{m}$. in this house (alternative) is almost the greatest, such a rational solution as the elimination of cold bridges, wall bearing capacity, durability and environmental friendliness potential, aesthetics of the exterior elements led to the obtained result.
Table 11

The neutrosophic full multiplicative form objective for the alternatives.

\begin{tabular}{lllll}
\hline & $S\left(A_{j}\right)$ & $S\left(B_{j}\right)$ & $U_{j}$ & Rank \\
\hline A1 & $0.0020 \times 10^{-5}$ & 0.0001 & 0.0003 & 5 \\
A2 & $0.0015 \times 10^{-5}$ & 0.0001 & 0.0002 & $3-4$ \\
A3 & $0.0081 \times 10^{-5}$ & 0.0000 & 0.0025 & 2 \\
A4 & $0.1174 \times 10^{-5}$ & 0.0004 & 0.0026 & 1 \\
A5 & $0.0305 \times 10^{-5}$ & 0.0014 & 0.0002 & $3-4$ \\
\hline
\end{tabular}

The sensitivity of created building elements' and materials' selection model was studied using the additional survey results of nine prospective customers who do not have experience in the house design field. According to customers' opinions, we have formed nine additional criteria weights' evaluations, which are given in Table 13. The sensitive study results are presented in Fig. 2.

In Fig. 2 the "Test 1" corresponds to qualified experts' opinions and designing firms practice "Test 2-Test 10" corresponds to nine clients assessment information. It is easy to notice that this our proposed model gives very similar alternatives assessment: both experts and inexperienced clients. The performed sensitivity study only confirms the reliability of the proposed model as there are no drastic changes in alternative ranking.

Future research

Since 2018 January EU enters into force on new building sustainability requirements: "A+" energy performance class, and since 2021 January-"A+ +". The requirements will be applied to all new buildings, which will be built after this date. In further study, there will be proposed prospects and opportunities to residential buildings' regarding new technical construction requirements for energy efficiency class "A+" for EU climatic conditions.

\section{Conclusions}

Increasing number of single-family residential houses' parameters is connected with more stringent sustainability requirements for buildings. A wide range of suitable building materials in the market gives lots of design possibilities. Therefore, during the design process of the single family residential house, it is possible to formulate a broad range of house design options, which further complicate the optimal (final) house project selection.

Proposed solution for a single-family residential house materials' and elements' selection problem is formulated applying MCDM framework. The new extension of the crisp MULTIMOORA method namely MULTIMOORA-SVNS allows taking into assessment the indeterminacy of the initial decision making information.

Table 10

The neutrosophic reference point objective for the alternatives.

\begin{tabular}{|c|c|c|c|c|c|c|c|c|c|c|}
\hline & $x_{1}$ & $x_{2}$ & $x_{3}$ & $x_{4}$ & $x_{5}$ & $x_{6}$ & $x_{7}$ & $x_{8}$ & $\max \left|D\left(r_{i}-w_{i}\left(x_{n}^{*}\right)_{i j}\right)\right|$ & Rank \\
\hline A1 & 0.1410 & 0.0597 & 0.9660 & 0.9529 & 0.9468 & 0.9843 & 0.9841 & 0.0081 & 0.9843 & 5 \\
\hline A2 & 0.0993 & 0.0459 & 0.9660 & 0.9788 & 0.9412 & 0.9741 & 0.9780 & 0.0309 & 0.9788 & 4 \\
\hline A3 & 0.1089 & 0.0597 & 0.9660 & 0.9081 & 0.9625 & 0.9640 & 0.9704 & 0.0081 & 0.9704 & 2 \\
\hline A4 & 0.1821 & 0.1075 & 0.8426 & 0.9188 & 0.9367 & 0.9533 & 0.9629 & 0.0309 & 0.9629 & 1 \\
\hline A5 & 0.2389 & 0.3026 & 0.8426 & 0.9188 & 0.9760 & 0.9478 & 0.9737 & 0.0239 & 0.9760 & 3 \\
\hline
\end{tabular}


Table 12

The rankings of the alternatives by neutrosophic MULTIMOORA approach.

\begin{tabular}{|c|c|c|c|c|}
\hline & The neutrosophic ratio system & The neutrosophic reference point & The neutrosophic full multiplicative form & Final rank \\
\hline A1 & 4 & 5 & 5 & 5 \\
\hline A2 & 2 & 4 & $3-4$ & 3 \\
\hline A3 & 1 & 2 & 2 & 2 \\
\hline A4 & 3 & 1 & 1 & 1 \\
\hline A5 & 5 & 3 & $3-4$ & 4 \\
\hline
\end{tabular}

Table 13

Weight of the tests for sensitivity analysis.

\begin{tabular}{lllllllll}
\hline & $x_{1}$ & $x_{2}$ & $x_{3}$ & $x_{4}$ & $x_{5}$ & $x_{6}$ & $x_{7}$ & $x_{8}$ \\
\hline Test 2 (client 1) & 0.40 & 0.07 & 0.02 & 0.10 & 0.05 & 0.2 & 0.15 & 0.01 \\
Test 3 (client 2) & 0.30 & 0.10 & 0.08 & 0.10 & 0.07 & 0.15 & 0.15 & 0.05 \\
Test 4 (client 3) & 0.15 & 0.13 & 0.09 & 0.11 & 0.15 & 0.15 & 0.15 & 0.07 \\
Test 5 (client 4) & 0.23 & 0.15 & 0.10 & 0.10 & 0.10 & 0.22 & 0.09 & 0.01 \\
Test 6 (client 5) & 0.20 & 0.20 & 0.08 & 0.08 & 0.10 & 0.20 & 0.08 & 0.06 \\
Test 7 (client 6) & 0.22 & 0.20 & 0.10 & 0.07 & 0.07 & 0.20 & 0.05 & 0.05 \\
Test 8 (client 7) & 0.20 & 0.20 & 0.20 & 0.05 & 0.05 & 0.20 & 0.05 & 0.05 \\
Test 9 (client 8) & 0.30 & 0.20 & 0.15 & 0.05 & 0.05 & 0.15 & 0.05 & 0.05 \\
Test 10 (client 9) & 0.25 & 0.20 & 0.10 & 0.08 & 0.05 & 0.25 & 0.04 & 0.03 \\
\hline
\end{tabular}

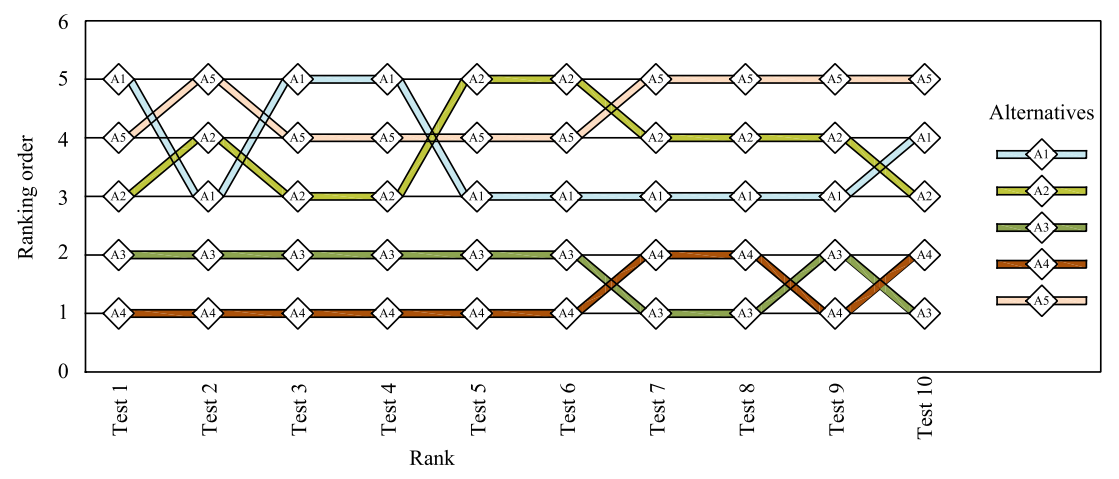

Fig. 2. Sensitive analysis illustration.

The research was performed constructing five alternatives for material selection of use single-family residential house which has the same architectural solution. Alternatives are the result of a generalisation of practical observations derived from proficiency of the design companies. According to the feedback of leading companies, the alternatives are constructed, and criteria values are assigned. The alternative selection was formulated including the following criteria: the price of the main elements, bearing walls load-bearing capacity, solutions for thermal bridges' elimination, localisation, environmental friendliness and durability potentials, aesthetics and floor slab weight. The criteria weights are determined by SWARA method. The experts stressed on the fact that the price of the main elements must have the greatest impact on the materials' selection. The analysis of the criteria estimates of the best 4-th alternative shows that the estimates of elimination of cold bridges, wall bearing capacity, durability and environmental friendliness potential, aesthetics of the exterior elements led to the optimal result. Therefore, the inclusion of the sustainability aspects of the materials' selection problem for the single family residential house is becoming more relevant. Thus, the more detailed analysis of these aspects and their interaction is useful for further assessments in multiple material selections for building quality.

Observing at the results of the sensitivity of the parameters it is easy to notice that this our proposed model gives very similar alternatives assessment for both cases: experts and inexperienced clients. The sensitivity study only confirms the reliability of our proposed solution for a single-family residential house materials' and elements' selection problem. This new theoretical composite model for the selection of single-family house elements and materials can be practically applied in creating the decision support system.

\section{References}

Alchapar, N.L., Correa, E., 2016. Aging of roof coatings, Solar reflectance stability according to their morphological characteristics. Constr. Build. Mater. 102, 297-305. http://dx.doi.org/10.1016/j.conbuildmat.2015.11.005.

Altuntas, S., Dereli, T., Yilmaz, M.K., 2015. Evaluation of excavator technologies: application of data fusion based MULTIMOORA methods. J. Civ. Eng. Manag. 21 (8), 977997. http://dx.doi.org/10.3846/13923730.2015.1064468.

Baglivo, C., Congedo, P.M., 2016. High performance precast external walls for cold climate by a multi-criteria methodology. Energy 115 (1), 561-576. http://dx.doi.org/10. 1016/j.energy.2016.09.018.

Baglivo, C., Congedo, P.M., Fazio, A., 2014. Multi-criteria optimization analysis of external walls according to ITACA protocol for zero energy buildings in the Mediterranean climate. Build. Environ. 82, 467-480. http://dx.doi.org/10.1016/j.buildenv.2014.09. 019.

Bausys, R., Zavadskas, E.K., 2015. Multicriteria decision making approach by VIKOR under interval neutrosophic set environment. Econ. Comput. Econ. Cybern. Stud. Res. Bucharest: Acad. Econ. Stud. (ISSN: 0424-267X) 49 (4), 33-48.

Bausys, R., Zavadskas, E.K., Kaklauskas, A., 2015. Application of neutrosophic set to multicriteria decision making by COPRAS. Econ. Comput. Econ. Cybern. Stud. Res. Bucharest: Acad. Econ. Stud. (ISSN: 0424-267X) 49 (2), 91-106.

Brauers, W.K.M., Zavadskas, E.K., 2010. Project management by MULTIMOORA as an instrument for transition economies. Technol. Econ. Dev. Econ. 16 (1), 5-24.

Brauers, W.K.M., Zavadskas, E.K., 2011. MULTIMOORA optimization used to decide on a bank loan to buy property. Technol. Econ. Dev. Econ. 17 (1), 174-188. http: //dx.doi.org/10.3846/13928619.2011.560632.

Chau, K.W., Wu, C.L., 2010. A hybrid model coupled with singular spectrum analysis for daily rainfall prediction. J. Hydroinf. 12 (4), 458-473. http://dx.doi.org/10.2166/ hydro.2010.032.

Ciancio, D., Jaquin, P., Walker, P., 2013. Advances on the assessment of soil suitability for rammed earth. Constr. Build. Mater. 42, 40-47. http://dx.doi.org/10.1016/j. conbuildmat.2012.12.049.

Cuadrado, J., Zubizarreta, M., Pelaz, B., Marcos, I., 2015. Methodology to assess the environmental sustainability of timber structures. Constr. Build. Mater. 86, 149-158. http://dx.doi.org/10.1016/j.conbuildmat.2015.03.109. 
Dezhi, L., Yanchao, C., Hongxia, C., Kai, G., Hui, E.C., Yangd, J., 2016. Assessing the integrated sustainability of a public rental housing project from the perspective of complex eco-system. Habitat Int. 53, 546-555. http://dx.doi.org/10.1016/j.habitatint.2016. 01.001.

EUR-Lex,, 2010. 32010L0031:Directive2010/31/EU of the European Parliament and of the Council of 19 May 2010 on the energy performance of buildings (accessed 16.05.03).

Eurostat,, 2014. Statistics Explained. http://ec.europa.eu/eurostat/statistics-explained/ index.php/Housing_statistics/lt, (accessed 16.05.03).

Ferrari, C., Touchaei, A.G., Sleiman, M., Libbra, A., Muscio, A., Siligardi, C., Akbari, H., 2014. Effect of aging processes on solar reflectivity of clay roof tiles. Adv. Build. Energy Res. 8 (1), 28-40. http://dx.doi.org/10.1080/17512549.2014.890535.

Gagliano, A., Detommaso, M., Nocera, F., Evola, G., 2015. A multi-criteria methodology for comparing the energy and environmental behavior of cool, green and traditional roofs. Build. Environ. 90, 71-81. http://dx.doi.org/10.1016/j.buildenv.2015.02.043.

Gori, P., Guattari, C., Evangelisti, L., Asdrubali, F., 2016. Design criteria for improving insulation effectiveness of multilayer walls. Int. J. Heat Mass Transfer 103, 349-359. http://dx.doi.org/10.1016/j.ijheatmasstransfer.2016.07.077.

Hafezalkotob, A., Hafezalkotob, A., 2015. Comprehensive MULTIMOORA method with target-based attributes and integrated significant coefficients for materials selection in biomedical applications. Mater. Des. 87, 949-959. http://dx.doi.org/10.1016/j. matdes.2015.08.087.

Hafezalkotob, A., Hafezalkotob, A., 2017. Interval target-based VIKOR method supported on interval distance and preference degree for machine selection. Eng. Appl. Artif. Intell. 57, 184-196. http://dx.doi.org/10.1016/j.engappai.2016.10.018.

Han, Y., Taylor, J.E., Pisello, A.L., 2017. Exploring mutual shading and mutual reflection inter-building effects on building energy performance. Appl. Energy 185 (2), 15561564. http://dx.doi.org/10.1016/j.apenergy.2015.10.170.

Hee, W.J., Alghoul, M.A., Bakhtyar, B., Elayeb, O., Shameri, M.A., Alrubaih, M.S., Sopian, K., 2015. The role of window glazing on day lighting and energy saving in buildings. Renewable Sustainable Energy Rev. 42, 323-343. http://dx.doi.org/10.1016/j.rser. 2014.09.020.

Hester, J., Gregory, J., Kirchain, R., 2017. Sequential early-design guidance for residential single-family buildings using a probabilistic metamodel of energy consumption. Energy Build. 134, 202-211. http://dx.doi.org/10.1016/j.enbuild.2016.10.047.

Holmstedt, L., Brandt, N., Robert, K.H., 2017. Can stockholm royal seaport be part of the puzzle towards global sustainability?-From local to global sustainability using the same set of criteria. J. Cleaner Prod. 140 (1), 72-80. http://dx.doi.org/10.1016/j. jclepro.2016.07.019.

Kamali, M., Hewage, K., 2017. Development of performance criteria for sustainability evaluation of modular versus conventional construction methods. J. Cleaner Prod. 142 (4), 3592-3606. http://dx.doi.org/10.1016/j.jclepro.2016.10.108.

Kersuliene, V., Zavadskas, E.K., Turskis, Z., 2010. Selection of rational dispute resolution method by applying new step-wise weight assessment ratio analysis (SWARA). J. Bus. Econ. Manag. 11 (2), 243-258.

Kosanovic, S., Fikfak, A., 2016. Development of criteria for ecological evaluation of private residential lots in urban areas. Energy Build. 115, 69-77. http://dx.doi.org/10.1016/ j.enbuild.2015.02.037.

Kuznik, F., Johannes, K., Franquet, E., Zalewski, L., Gibout, S., Tittelein, P., Dumas, J.P., David, D., Bedecarrats, J.P., Lassue, S., 2016. Impact of the enthalpy function on the simulation of a building with phase change material wall. Energy Build. 126, 220-229. http://dx.doi.org/10.1016/j.enbuild.2016.05.046.

Liu, H.-C., Fan, X.-J., Li, P., Chen, Y.-Z., 2014. Evaluating the risk of failure modes with extended MULTIMOORA method under fuzzy environment. Eng. Appl. Artif. Intell. 34, 168-177. http://dx.doi.org/10.1016/j.engappai.2014.04.011.

Lizana, J., Barrios-Padura, A., Molina-Huelva, M., Chacartegui, R., 2016. Multi-criteria assessment for the effective decision management in residential energy retrofitting. Energy Build. 129, 284-307. http://dx.doi.org/10.1016/j.enbuild.2016.07.043.

Mardani, A., Jusoh, A., Zavadskas, E.K., 2015. Fuzzy multiple criteria decision-making techniques and applications-two decades from 1994 to 2014. Experts Syst. Appl. 42 (8), 4126-4148. http://dx.doi.org/10.1016/j.eswa.2015.01.003.

Motuziene, V., Rogoza, A., Lapinskiene, V., Vilutiene, T., 2016. Construction solutions for energy efficient single-family house based on its life cycle multi-criteria analysis: a case study. J. Cleaner Prod. 112, 532-541. http://dx.doi.org/10.1016/j.jclepro.2015. 08.103.

Mulliner, E., Smallbone, K., Maliene, V., 2013. An assessment of sustainable housing affordability using a multiple criteria decision making method. Omega 41 (2), 270279. http://dx.doi.org/10.1016/j.omega.2012.05.002.

Nakhaei, J., Arefi, S.L., Bitarafan, M., Kildiene, S., 2016a. Evaluation of light supply in the public underground safe spaces by using of COPRAS-SWARA methods. Int. J. Strateg. Prop. Manag. 20 (2), 198-206. http://dx.doi.org/10.3846/1648715X.2015.1132790.
Nakhaei, J., Bitarafan, M., Arefi, S.L., Kaplinski, O., 2016b. Model for rapid assessment of vulnerability of office buildings to blast using SWARA and SMART methods (a case study of Swiss re tower). J. Civ. Eng. Manag. 22 (6), 831-843. http://dx.doi.org/10. 3846/13923730.2016.1189457.

Oree, V., Sayed Hassen, S.Z., Fleming, P.J., 2017. Generation expansion planning optimisation with renewable energy integration: A review. Renewable Sustainable Energy Rev. 69, 790-803. http://dx.doi.org/10.1016/j.rser.2016.11.120.

Peng, J.J., Wang, J.Q., Zhang, H.Y., Chen, X.H., 2014. An outranking approach for multi-criteria decision-making problems with simplified neutrosophic sets. Appl. Soft Comput. 25, 336-346. http://dx.doi.org/10.1016/j.asoc.2014.08.070.

Pombo, O., Allacker, K., Rivela, B., Neila, J., 2016. Sustainability assessment of energy saving measures: A multi-criteria approach for residential buildings retrofitting-a case study of the Spanish housing stock. Energy Build. 116, 384-394. http://dx.doi.org/ 10.1016/j.enbuild.2016.01.019.

Raina, P., Sohel, N., Oremus, M., Shannon, H., Mony, P., Kumar, R., 2015. Assessing global risk factors for non-fatal injuries from road traffic accidents and falls in adults aged 35-70 years in 17 countries: a cross-sectional analysis of the Prospective Urban Rural Epidemiological (PURE) study. US National Library of Medicine National Institutes of Health, 17. http://dx.doi.org/10.1136/injuryprev-2014-041476.

Ramírez-Villegas, R., Eriksson, O., Olofsson, T., 2016. Assessment of renovation measures for a dwelling area -impacts on energy efficiency and building certification. Build. Environ. 97, 26-33. http://dx.doi.org/10.1016/j.buildenv.2015.12.012.

Rid, W., Lammers, J., Zimmermann, S., 2017. Analysing sustainability certification systems in the German housing sector from a theory of social institutions. Ecol. Indic. 76, 97-110. http://dx.doi.org/10.1016/j.ecolind.2016.12.022.

Sandanayake, M., Zhang, G., Setunge, S., 2016. Environmental emissions at foundation construction stage of buildings - two case studies. Build. Environ. 95, 189-198. http://dx.doi.org/10.1016/j.buildenv.2015.09.002.

Smarandache, F.A., 1999. Unifying field in logics. In: Neutrosophy: Neutrosophic Probability, Set and Logic. American Research Press, Rehoboth, USA.

SPCS,, 2016. SE Certification Center of Building Products, Estimated market prices of Construction XXVIII, Order no. B-16-010, Vilnius. http://www.spsc.lt/cms/index. php? Itemid = 326 (accessed 16.03.30).

Stanujkic, D., Karabasevic, D., Zavadskas, E.K., 2015. A framework for the selection of a packaging design based on the SWARA method. Inzinerine Ekon.-Eng. Econ. 26 (2), 181-187. http://dx.doi.org/10.5755/j01.ee.26.2.8820.

Taormina, R., Chau, K.W., 2015. Data-driven input variable selection for rainfall-runoff modeling using binary-coded particle swarm optimization and extreme learning machines. J. Hydrol. 529 (3), 1617-1632. http://dx.doi.org/10.1016/j.jhydrol.2015. 08.022 .

Toni, A., Pakkala, T.A., Kolio, A., Lahdensivu, J., Kiviste, M., 2014. Durability demands related to frost attack for Finnish concrete buildings in changing climate. Build. Environ. 82, 27-41. http://dx.doi.org/10.1016/j.buildenv.2014.07.028.

Turskis, Z., Daniunas, A., Zavadskas, E.K., Medzvieckas, J., 2016. Multicriteria evaluation of building foundation alternatives. Comput.-Aided Civ. Infrastruct. Eng. 31 (9), 717 729. http://dx.doi.org/10.1111/mice.12202.

Turskis, Z., Juodagalviene, B., 2016. A novel hybrid multi-criteria decision-making model to assess a stairs shape for dwelling houses. J. Civ. Eng. Manag. 22 (8), 1078-1087. http://dx.doi.org/10.3846/13923730.2016.1259179.

Vucicevic, B., Jovanovic, M., Afgan, N., Turanjanin, V., 2014. Assessing the sustainability of the energy use of residential buildings in Belgrade through multi-criteria analysis. Energy Build. 69, 51-61. http://dx.doi.org/10.1016/j.enbuild.2013.10.022.

Wang, W.C., Chau, K.W., Xu, D.M., Chen, X.Y., 2015. Improving forecasting accuracy of annual runoff time series using ARIMA based on EEMD decomposition. Water Resour. Manag. 29 (8), 2655-2675. http://dx.doi.org/10.1007/s11269-015-0962-6.

Wu, C.L., Chau, K.W., Fan, C., 2010. Prediction of rainfall time series using modular artificial neural networks coupled with data-preprocessing techniques. J. Hydrol. 389 (1-2), 146-167. http://dx.doi.org/10.1016/j.jhydrol.2010.05.040.

Zavadskas, E.K., Antucheviciene, J., Hajiagha, S.H.R., Hashemi, S.S., 2015a. The intervalvalued intuitionistic fuzzy multimoora method for group decision making in engineering. Math. Probl. Eng. 13. http://dx.doi.org/10.1155/2015/560690. Article ID 560690 .

Zavadskas, E.K., Bausys, R., Lazauskas, M., 2015b. Sustainable assessment of alternative sites for the construction of a waste incineration plant by applying WASPAS method with single-valued neutrosophic set. Sustainability 7 (12), 15923-15936. http://dx. doi.org/10.3390/su71215792.

Zhang, J., Chau, K.W., 2009a. Multilayer ensemble pruning via novel multi-sub-swarm particle swarm optimization. J. UCS 15 (4), 840-858. http://dx.doi.org/10.3217/ jucs-015-04-0840.

Zhang, S., Chau, K.W., 2009b. Dimension reduction using semi-supervised locally linear embedding for plant leaf classification. Lect. Notes Comput. Sci. 5754, 948-955. http://dx.doi.org/10.1007/978-3-642-04070-2_100. 